\title{
A New Paradigm of Sustainability
}

\author{
Shaharir b. M. Z \\ Pusat Dialog Peradaban, Universiti Malaya \\ PO box 50603, Kuala Lumpur, Malaysia
}

Tel: 60-1-2236-1967Ｅ-mail: riramzain@yahoo.com

\author{
Received: October 8, 2011 \\ Accepted: November 22, $2011 \quad$ Published: January 1, 2012 \\ doi:10.5539/jsd.v5n1p91 \\ URL: http://dx.doi.org/10.5539/jsd.v5n1p91
}

The research is financed by Universiti Malaya Research Grant RG122/11SUS

\begin{abstract}
We show that the well known and popular Braundtland Commision's 1987 definition of sustainability is an optimization problem and similarly with its improvements. Based on historical factors, discourses and controversies on sustainability-nonsustainability, and proven nature of human needs, we show that the present definitions of sustainability are not comprehensive enough to cover the many important factors of sustainability which include the spiritual and cultural dimensions of man and knowledge; and in fact, each definition also actually and implicitly inherites values which inhibit sustainability. Furthermore, we show that the present mode of decision making is based on extremism, a proven characteristic of nonsustainability. Accordingly, we propose a new concept of decision making based on Islamic moderation known as wusta. This new paradigm of optimization together with our consideration of the comprehensiveness of proven factors of sustainability and the proven nature of human needs mentioned above, we define a new sustainability concept accordingly, which we hope to establish a new paradigm in the science of sustainability.
\end{abstract}

Keywords: Economic development, Sustainable development, Islamic economic development, Islamic sustainable development

\section{Introduction}

There are many definitions of sustainability since its emergence in the 1970s (internet 1 and Kates et al., 2005). However it is no doubt that the most common definition of sustainability is on development, sustainable development, by the Brundtland Commision 1987 which defines sustainable development as "a development that meets the needs of the present without compromising the needs of future generations to meet their own needs." This definition has been criticized by many to the extent that the economics (as presently defined and practiced) for development is not sustainable, thus sustainable development has reached a level of an oxymoron (Daly, 1990). Most of the arguments for this conclusion have been given by ecological and environmental economists; the earliest being Kapp (1950) and arrived at the peak, perhaps in 1990s notably by Postel (1990) and many others mentioned in section 2, but the reviews continue in this millennium notably by Hopwood et al. (2005) and others which will be discussed further later on in the same section.

Based on relevant articles appear in the Sustainability Science since its inception, reveal that the subject deals with environmental and ecological issues (climate change, ecological economics or systems, energy and resources, forestry (agroforestry, biodiversity, deforestation, tropical rain forest), land degradation, land use change, soil, water scarcity, and wildlife), food (agriculture), fishery (depletion of marine fish stocks), the nature of development or economic development, urban planning, rural sociology, tourism, business, capitalism (capitalistic system), health (global ill-health), lifestyle, and population growth and distribution (Jerneck et al., 2011; Kajikawa, 2008; Kajikawa et al., 2007; Savag, 2006). Education as an issue in sustainability is relatively new, and when dealing with this aspect of sustainability, Segalas et al. (2009) discuss competencies (knowledge and understanding, skills and abilities, and attitudes), Makarov (2010) discusses only on intellectual capital, Lan (2008) on vocational education and Rao et al. (2008) on the cost of adequate education. These are insufficient especially considering that the issue should be expanded to knowledge sustainability. A recognition for a need for knowledge sustainability is only indirectly proposed by Li and Pak (2010) when they discuss how the present ICT, specifically the Web 2.0 , have not been fully utilized for the purpose of sustainable knowledge sharing. We believe that knowledge sustainability is one of the important components in any sustainability issue which has 
been neglected. Knowledge sustainability is not just the issue of knowledge dissemination or knowledge sharing only. Another interesting issue to us is the sustainability of a culture where so far it has been discussed only in relation with tourism (Chew, 2009); and spiritualism is even more unsatisfactory to us because it is minimally discussed even though its importance is increasingly manifested as shown in our discussion below.

In a separate section we will show that a sustainability definition (programme) based on optimization is another oxymoron. But before that we would like make a brief survey on proven and controversial factors of unsustainability, and various initiatives of sustainability proposed by the many scholars to date. Then we obtained the sustainability factors which we think are still relevant and more importantly are the factors which have not been considered but we believed that they are very relevant to sustainability. We also examine the human needs which are relevant to any definition/programme of sustainability vis-à-vis our own value system.

Finally, we propose a new definition of sustainability based on, among others, those factors of unsustainability and our new concept of best practice to replace the optimization paradigm and a new meaning of human needs and purpose in life.

\section{Factors of Unsustainability}

Almost all historians agree that the fall of a civilization is due to practices of various extremism: extremal use or exploitation of natural resources, extreme irrigation or topographical change of land, extreme number of population (overpopulated), extreme taxation, extreme social chaos (due to wars and rebellions) (see for example Hardesty, 2001). The effects of these extremism, namely unsustainable civilization or society in the West in the 16th century until at least the 20th century were minimal due to the colonization policy, or in the case of overpopulation and overtaxation are due to government initiatives (such as a policy of zero population growth) and change in value system of the Western society, even though country like UK is still well known for its high taxation policy. However wars and rebellions are still rampant and most are linked to political interests of the Westerners in their past colonies because they have found that these were necessary for their sustainability (at the expense of other people's sustainability) which is another form of extremism, namely materialism, ethnocentricism or nationalism, and globalism.

At the same time secularism, deism, naturalism and atheism (considered to be the four "new" religions), are becoming more dominant in replacing the traditional religions. These new religious or even antireligious or areligious values are dominantly articulated in the present knowledge, and this is included in sustainability science, not realizing or just plain antagonistic towards traditional or perennial philosophy and values that these very values undermined sustainability. These religious, ethical and moral values or adab (in Islamic teaching), which are clearly counter to these extremism and hence promoting sustainability, are left out, neglected or simply abandoned. Thus, it is inappropriate and misleading for some Western ecological-enviromental economists, started by White in 1967, to blame Christian teaching for the state of the present environment, whereas the real culprits are those capitalists, development economists, and neoliberalists who are areligious or who disregarded any religion whatsoever. However, positive discourses on Christianity and environments have been going on since then as shown by writers in the 1990's as shown in papers by Gore (1993), Gottlieb (1996), Daly (1996) and Enderle (1997), and in this millennium: Glenna (2002), Gardner (2003), Sideris (2007), Hitzhusen (2007), and White (2010); and each of them is either supporting or refuting or even reconciling the two opposing views on Christian religion and environment.

Yet others (the earliest being Kapp, 1950) had criticized the over-emphasis on the homo oeconomicus in the well known subject, economics, at the expense of homo politicus and homo sustenensus of human, and the negligence of environmental and ecological aspects of sustainability at the expense of the actual issues of human sustainability other than just the socalled physiological needs of human beings which also include cultural and spiritual needs. (Examples of recent writings on this issue are notably by Postel (1990), Redman (1999), Faber et al. (2003), Hopwood et al. (2005), Magnani and Tubb (2008), and Li (2011)). These are the issues which are dealt with in this paper, highlighting a need for a new definition of sustainability.

A controversial empirical findings on the relationship between prosperity (=income) and environments, which is known as the Kuznet curve, as reviewed by Bartelmus (2008) together with the empirical evidence that development is irrelevant to happiness as shown by many (Max-Neef, 1995; Hamilton, 2004; Diener \& Seligman, 2004; Shaharir, 2008), we believe, should be a sufficient proof to include happiness as part of a new definition of sustainability. Similarly with the definition of human needs (deficiently defined by Bartelmus (2008) as human welfare) should also be properly and clearly expressed in the definition of sustainability based on a much more holistic view of man.

As we have mentioned earlier, a comprehensive science of sustainability must include the issue of poverty or 
deteriorating level of knowledge and culture. It has been shown historically that the fall of a civilization (hence a non-sustainability of human kind) is the collapse of good knowledge and culture. These two aspects of sustainability are being neglected as such that they need to be addressed deeper and more comprehensively than those discussed by Chew (2009) on cultural heritage for tourism and Makarov (2010) on intellectual capital.

It is interesting also to note that $\mathrm{Li}$ (2011, Chapter 1) present a review on sustainable development in the past 30 years whereby the author makes a conclusion that "the major world view" on the present conceptual framework for sustainable development must be changed to "a more balanced and holistic" view but without elaborating the exact nature of the intended world view. In fact, his/her focus on the 27 key principles of the Rio Declaration is just inappropriate to his/her well intended view. However, Li's presentation on the scope, definitions and policies of sustainability in Australia, China, UK, USA and Singapore is even more relevant to our discussion in this paper because it provides very interesting and important major initiatives on sustainability by these governments and yet each of these initiatives is still neglecting our major components of sustainability, and those are religion, language and knowledge sustainability.

\section{An Optimal Planning and Non-Sustainability}

It looks as though most agree that a sustainable decision is an optimal decision in which when it is implemented the relevant product is sustainable with respect to a definition of sustainability, even though Jaeger (1995) questioned this tacit agreement. Indeed, many specific optimization models (with respect to the present definition of optimality and sustainability) have been "successfully formulated" in ecological, agricultural, and business domains as shown by Smorch (2010), Geunes and Pardalos (2005) and Zhou et al. (2000) in supply chain; Klemes et al. (2010) in industrial processing; and Heinzle et al. (2007) in bioprocesses. Moreover, surprisingly, and recently, the architectural design for the National Aquatic Center (for the 2008 Olympic) at Beijing was hailed as a sustainable architectural design in the sense that it is "effective, perfect, or useful as possible" (Internet 2).

In economics, as mentioned earlier, the most interesting issue so far is sustainable development. Mathematically, one has to develop a visionary economic planning (not necessary development) model first before formulating a policy for achieving sustainability (a sustainable planning policy). The relationship between optimization and sustainability has been studied since 1928 when Ramsay first introduced a development model based on utility optimization which produced an optimal consumption but proved to be not sustainable. Thus, the model has undergone various changes. Farzin (2010) reviews this type of optimization model for achieving sustainability beginning with the Ramsay model to Sollow-Hartwick model in the 1970s and others, and ending with his own model developed in 2006. Of course, Farzin proves that his model produces sustainable economic policy but he himself says that the policy is not only impractical but is more suitable for rich countries only. Then he suggests a mixture of the optimal solution and his rationalization outside the scope of his optimization; thus, it is of theoretical interest only. One of the intrinsic weaknesses of these optimization approaches is the well known weakness of the utility approach in multiobjective optimization. Thus, we are not interested in this approach in preference to the actual multiobjective optimization which is more appropriate to the definition of the sustainability that we are interested in. Other approaches are found extensively in Islam (2001) and Bartelmus (2008). Of course, a formal multiobjective optimization problem in an economic development or planning is yet to be formulated in a sufficiently general enough form so as to represent a standard economic development or planning. This issue in relation to sustainability is comprehensively discussed by Bartelmus (2008) and therefore we have decided to concenterate on his model of a development and sustainability.

After a review of the state of the art of sustainable development, Bartelmus (2008) defines what he called an operational definition of sustainable development as "the set of development programs that meets the targets of human needs satisfaction without violating long-term natural resources capacities and standards of enviromental quality and social equity". This is in fact less general than the Brundtland Commision's definition of sustainability stated earlier in our introduction. Bartelmus definition is less general because he makes explicit statements on two aspects: the goals rather than objectives, and the details of "the needs of the future generations" in terms of specific physical resources (natural and environmental) and equity. However, clearly both definitions are development plannings involve multiobjective and multigoal optimization problems, i.e a multiobjective optimization problem for Bruntland sustainability development and a multigoal optimization for the Bartlemus sustainability development respectively. The objective functions of present needs and the goals are the targets of human needs satisfaction. The goals which many are interested in (especially the Third World) are the eight goals in the UN Millennium Development Goals (MDG) which includes goals for the eradication of poverty and hunger, eradication of diseases (in particular AIDS and malaria), and still a vaid and subjective goal namely environmental sustainability (complete lists are in Bartelmus 2008). Those goals are subjected to the Bartelmus 
constraints: "without violating long-term natural resources capacities and standards of enviromental quality and social equity"; whereas those objectives are subjected to the Brundtland Commision constraints: "without compromising..." which are more general than the earlier mentioned constraints; and both constraints could be represented by a relevant set of differential equations. It is interesting to note that Bartelmus 2008 does not formulate explicitly his sustainability programme in terms of multigoal or multiobjective optimization.

Later, with our new paradigm for optimization and hence on sustainability, both are extended to religious domain, and hence we formulate a more general optimal control model (an optimization model) than the above proposed model.

\section{A New Paradigm for Optimization and Sustainability}

In this section we will discuss the reasons for a new paradigm of optimization in connection with sustainability. Shaharir and Rohani (1996), and Shaharir $(2003 ; 2005$; 2006) have argued that the present concept of optimization is based on greed and extremism or moulded in those values from democratic (neo)-liberalism, capitalism, socialism, to secularism and elitism. Thus in the present paradigm, an optimal decision necessarily means a better decision which attains a superlative level: the most, the highest, the biggest, etc. or the least, the lowest, or the smallest etc. value of a certain performance measure such as productions, profit, loss, risk, needs etc. This is certainly extremism, a kind of value which is very much in tandem with capitalism and liberalism. Mathematics itself shows that this classical definition is untenable (no decision exists) in the case of a multiobjective optimization planning. In an attempt to rectify this definition, it is thought that in practice no one really made such a decision because of urgency so that a decision is made based on restricted knowledge and the result is that the optimal decision is not as extreme as the original optimal decision, but still it is a kind of extreme with respect to a particular situation. This is Simon 1957 optimal decision based on his model of a man in which he characterised man as no longer a rational being but a bounded rational being. The concept is mathematically implemented under the name of "goal optimization" or "goal programming" by Charnes and Cooper (1961). This is the first paradigm shift in optimization from a purely rational capitalistic view based to a bounded-rational capitalistic view based. Despite its shortcomings (as shown by many writers on a discussion of other definitions of optimum which will be elaborated further later), the Simon optimal-decision is still popular especially in making a decision for a multiobjective planning, criteria, attributes, performances, or other measures known in decision science. In fact, Bartelmus' 2008 definition of sustainability is explicitly suited for a goal programming.

There is another optimum measure which is more popular among economists namely that introduced by an Italian economist-politician during the Nazism and Fascism turmoil in Europe. He believes in laissez-faire economics, liberalism and elitism against Fascism and dictatorship in Italy during Mussolini's era. Thus, he proposed a new paradigm in social fairness and optimal distribution of wealth in which a new concept of optimal decision emerged, known by various names and not just under his name, Pareto optimum/ decision/ policy/ instrument/ distribution, but also under very strong and assertive terms such as efficient decision etc, non-inferior decision etc. and non-dominated decision etc. In this new optimization paradigm, a set of performance measures or objectives achieved its optimum value if one of the measures or objectives achieved its extremal value, and the rest attained no less inferior values than their values by any other decisions. There are of course many other paradigms of optimizations other than these three types of optima (the classical, Simon and Pareto optima) and these are often reviewed in books such as Ehrgott and Ganibleaux (2002), Figueira et al. (2004) and Marler (2009) or articles by Sunar and Kahraman (2001), Freitas (2004); and Marler and Arora (2004). But those three paradigms mentioned earlier are most well known, and most widely used not only by theoreticians but also by practitioners in various fields.

We show that any of those three paradigms of optimization will most unlikely deliver a right decision for sustainability (as defined earlier in this paper). Perhaps this could be seen easily by focusing on the nature of a Pareto decision. A Pareto decision is clearly not people oriented but elitist because the decision maker would be happy to entertain only the need of one of the many objectives or performance measures (which implies one individual, an elite group or an economic sector) involved. The decision of this nature is obviously not in line with sustainability. Furthermore, since each of these three paradigms of optimization involved capitalism (in fact extremism, liberalism and elitism can only flourish in a capitalistic society), then we can use those arguments which show that capitalism is in contradiction with sustainability. For this we agree with Singer 2010 who argues that capitalism is a barrier to sustainability, and earlier Porritt (2006) who believes that a new form of capitalism (even though he is believed to be a staunch supporter of capitalism) has to be established for sustainability.

Other considerations to note are that the three paradigms of optimization neglected the spiritual dimension of a 
human being whereas sustainability must necessarily involve spiritual values or to be more precise, religious values, of which the one that we are most interested in are Islamic values. There are plenty of precepts of Islamic teachings (based on al-Qur'aan (Note 1) translated by Yusuf Ali) which are against extremism (for examples the terms wasters/musrifyyn 7:31; transgressors/mu'tadyyn 2:190; and spendthrifts/mubazziryyn 17:27), materialism/waradhuw bi al-hayat al-dunya (for example 10:7-8), greed/laa yunfiquwn/jama amaa lan wa'addadah (for examples in 9: 34, and 104: 1-4), individualism/qaturalyabkhaluw/bakhil (for examples in 17: 100, 3: 180, and 92: 8-10) etc., and since each of these values is related to the three concepts of optimality described above, then it is only proper, at least, to make some amendments to those three classical or established optimal concepts in order to achieve a better decision making for sustainabilty.

A critical evaluation of economic liberalism based on Islamic perspectives as presented by Choudhury 2008 naturally motivates us more towards a revision of the present paradigm of optimization. Even without the Islamic-value consideration, one would arrive at a similar conclusion. For example Cairns Jr. 2002 has already discussed the need for modern man to embrace "sacred values" (which is obviously just another name for a spiritual or religious values) for achieving sustainability; whereas Mabogunje 2004 argues that sustainability needs change of "current human values" (which is clearly a more spiritual or sacred nature than the present); and to compliment for all these needs it is interesting to note that Waytz 2010 who makes an exposition on reasons behind the positive aspect of embracing sacred values, and that is, it is not exchangeable with monetary values. Thus sacred values are very much needed for fighting against materialism which is a barrier for sustainability. This is also in line with the change in the objectives of an economic theory based on materialism (economics for wealth, physical development), secular-liberalism (economics for justice or prosperity), or socialism (welfare economics, economics for well being) into the happiness paradigm (very religiously value-laden) where its development is discussed recently by Shaharir 2008. In this respect, Liu 2010 discussion on the need for a definition of wealth which includes a spiritual wealth is very much relevant for a development of a new paradigm of sustainability proposed in this paper.

As far as the Islamic-values are concerned, in so far as the values which are related to optimal decision making, we have proposed a new paradigm of optimization based on the Islamic concept of moderation, just and balance, namely wusța (Note 2). This concept can be used in improving the Simon-optimal decision making but more meaningful in the innovation of the Pareto-optimal decision making. This involves a new definition of an optimal decision as follows:

A wusța or simply wusta (without a dot below t) policy is such that at least half of the performance measures achieve their classical optimal values and the rest attain no less values than by any other policies.

A wusta goal policy is such that each ordered performance measures achieves its classical optimal value one after the other according to the given priority.

Shaharir 2006 has shown that these new optimal policy in general are different from the classical optimal solution, the Pareto optimal solution, and in some way improves the Simon-optimal solution. We believe that these policies are better than those classical policies obtained from the present optimization paradigm and hence have the potential to produce more sustainable economic results.

\section{A New Definition of Sustainability}

The paradigm change in optimization (which is religiously value-laden) simultaneously creates a need for a change in the definition of sustainability so that it includes not just the non-spiritual or non-sacral nature of biological, chemical, physical sustainability and the sustainability of the interactions of the secular man and nature but it must include all creations (in religious sense, particularly Islam) and the Creator (the God, particularly Allah) so that the spiritual dimension of sustainability is indispensible. This would be called a generalized definition of the sustainability as follows:

Sustainability is a state of being achieving a wusta (moderate, middle way, balanced and just) level of physical, social, political, economical, science-knowledge, cultural and religio-spiritual needs of the present man without sacrificing the all relevant resources and all beings created by the God so that future generations will be able to enjoy at least the same level of happiness in this world and hereafter as the present generation.

The salient new features in this definition are the replacement of optimal level by a wusta level of consumptions (human needs), an explicit additional human need, "the spiritual need", emphasizing the satisfaction of human need as the "happiness", and long term or future generation is replaced by "this world and here-after". Thus, sustainability, in particular, is no longer an optimization problem but rather a wustaisation problem where we no longer have to optimize but rather to wustaise objectives or goals in life. 


\section{Conclusion}

Based on the spiritual dimension of man (Islamic values), we have shown that the present optimization paradigm is unacceptable and accordingly we introduce a new optimization paradigm and hence a new definition of sustainability based on Islamic values. This, we believe, is a better instrument for sustainability.

We hope to be able to mathematically formalise our new definition of sustainability given in section 5 above in our next paper, as a multiobjective wustaisation problem and hence obtain some new qualitative and quantitative nature of the sustainable policies based on our new optimality paradigm. We also hope that a generalized set of sustainability indices could be produced based on our new sustainability paradigm. Of course, the implications of these new findings would be studied as well in comparison with the present theories and applications.

\section{Acknowledgement}

The author appreciates Universiti Malaya for supporting this work under the Research Grant RG122/11SUS.

\section{References}

Bartelmus, P. (2008). Quantitative eco-nomics: how sustainable are our economies? New York: Springer.

Brundtland Commision. (1987). World commision on environment and development. Our common future. Oxford: Oxford University Press.

Cairns, J. Jr. (2002). Sustainability and sacred values. Ethics in Science and Environmental Politics, 15-27. [Online] Available: http://www.int-res.com/articles/esep/2002/article2.pdf

Charnes, A. \& Cooper, W. W. (1961). Management models and industrial applications of linear programming. New York: Wiley.

Chew, M. M. (2009). Cultural sustainability and heritage tourism development: problems in developing bun festival tourism in Hong Kong. Journal of Sustainable Development, 2 (3), 34-42.

Choudhury, M. A. (2008). Islam versus liberalism: contrasting epistemological inquiries. International Journal of Social Economics, 35 (4), 239-268. http://dx.doi.org/10.1108/03068290810854538

Daly, H. E. (1990). Sustainable growth: A bad oxymoron. Environmental Carcinogenesis Reviews, 8 (2), 401-407. http://dx.doi.org/10.1080/10590509009373395

Daly, H. E. (1996). Beyond growth. Boston, MA: Beacon.

Diener, E. \& Seligman, M. E. P. (2004). Beyond money: toward an economy of well-being. Psychological Science in the Public Interest, 5 (1), 1-31. http://dx.doi.org/10.1111/j.0963-7214.2004.00501001.x

Ehrgott, M. \& Gandibleux, X. (2002). Multiple criteria optimization: state of the art annotated bibliographic surveys. New York: Kluwer.

Enderle, G. (1997). In search of a common ethical ground: corporate environmental responsibility from the perspective of christian environmental stewardship. Journal of Business Ethics, 16 (2), 173-181(9).

Faber, M., Petersen, T. \& Schiller, J. (2002). Homo oeconomicus and homo politicus in ecological economics. Ecological Economics, 40, 323-333. http://dx.doi.org/10.1016/S0921-8009(01)00279-8

Farzin, Y. H. (2010). Sustainability, optimality, and development policy. Review of Development Economics, 14 (2), 262-281. http://dx.doi.org/10.1111/j.1467-9361.2010.00551.x

Figueira, J. R., Greco, S. \& Ehrgott, M. (2004). Multiple criteria decision analysis: state of the art surveys. New York: Springer.

Freitas, A. A. (2004). A critical review of multi-objective optimization in data mining: a position paper. $A C M$ SIGKDD Explorations Newsletter, 6 (2), 77 - 86. http://dx.doi.org/10.1145/1046456.1046467

Gardner, G. (2003). Engaging religion in the quest for a sustainable world. In the state of the world 2003. A Worldwatch Institute Report on progress toward a sustainable society (Ch. 8, pp 152-175). New York: Norton.

Geunes, J. \& Pardalos, P. M. (Eds.). (2005). Supply chain optimization. New York: Springer-Verlag.

Glenna, L. L. (2002). Liberal economics and the institutionalization of sin: christian and stoic vestiges in economic rationality. Worldviews: Global Religions, Culture, and Ecology, 6 (1), 31-57.

Gore, A. (1993). Earth in the balance. Ecology and the human spirit. New York: Plume, Penguin.

Gottlieb, R. S. (Eds.). (1996). This sacred earth: religion, nature, environment. New York: Routledge.

Hardesty, D. L. (2001). Archeology. In Tolba, M. K. (Eds.). Our fragile world. Challenges and opportunities for 
sustainable development. Oxford: Eolss.

Hamilton, C. (2004). Growth fetish. London: Pluto.

Heinzle, E., Biwer, A. P. \& Cooney, C. L. (2007). Development of sustainable bioprocesses: modeling and assessment. New York: Wiley.

Hitzhusen, G. (2007). Judeo-Christian theology and the environment: moving beyond scepticism to new sources for environmental education in the United States. Environmental Education Research, 13 (1), 55-74. http://dx.doi.org/10.1080/13504620601122699

Hopwood, B., Mellor, M. \& O’Brien G. (2005). Sustainable development: Mapping different approaches. Sustainable Development, 13, 38-52. http://dx.doi.org/10.1002/sd.244

Internet 1. The University of Reading. ECIFM (Enviromental Challenge in Farm Management). [Online] Available: http://www.ecifm.rdg.ac.uk/definitions.htm (July 25, 2010)

Internet 2. Kelvin's Conjecture: The Sustainability of Optimization and Integration. [Online] Available: http://greenlineblog.com/2008/06/kelvins-conjecture-the-sustainability-of-optimization-and-integration (July 24, 2010)

Islam, S. M. N. (2001). Optimal growth economics volume 252: an investigation of the contemporary issues and the prospect for sustainable growth. New York, North Holland.

Jaeger, W. K. (1995). Is sustainability optimal? Examining the differences between economists and environmentalists. Ecological Economics, 15 (1), 43-57. http://dx.doi.org/10.1016/0921-8009(95)00040-G

Jerneck, A., Olsson, L., Ness, B., Andelberg, S., Baier, M., Clark, E., Hickler, T., Hornborg, A., Kronsell, A., Lovbrand, E. \& Persson, J. (2011). Structuring sustainability science. Sustainability Science, 6 (1), 69-82. http://dx.doi.org/10.1007/s11625-010-0117-x

Kajikawa, Y. (2008). Research core and framework of sustainability science. Sustainability Science, 3 (2), 215-239. http://dx.doi.org/10.1007/s11625-008-0053-1

Kajikawa, Y., Ohno, J., Takeda, Y., Matsushima, K. \& Komiyama, H. (2007). Creating an academic landscape nof sustainability science: an analysis of the citation network. Sustainability Science, 2 (2), 221-231. http://dx.doi.org/10.1007/s11625-007-0027-8

Kapp, K. W. (1950). The social cost of private enterprise. Boston: Harvard Univ. Press.

Kates, R. W., Parris, T. M. \& Leserowitz, A. A. (2005). What is sustainabale development? Goals, indicators, values and practice. Environment: science and policy for sustainable development, 47 (3), 8-21. [Online] Available: http://www.hks.harvard.edu/sustsci/ists/docs/whatisSD_env_kates_0504.pdf (July 24, 2010)

Klemes, J., Friedler, F., Bulatov, I. \& Varbanov, P. (2010). Sustainability in the process industry: integration and optimization. New York: McGraw-Hill Professional.

Lan, J. (2008). A discussion on the ecological balance and sustainable development of higher vocational education. Journal of Sustainable Development, 1 (3), 48-50.

Li, R. Y. M. (2011). Building our sustainable cities. US: Common Ground Publishing.

Li, R. Y. M. \& Pak, D. H. A. (2010). Resistance and motivation to share sustainable development by Web 2.0. Journal of Information \& Knowledge Management, $9 \quad$ (3), 251-262. http://dx.doi.org/10.1142/S0219649210002656

Liu, Y. (2010). Establishing modern concept of wealth, prompting Chinese social sustainable development. Journal of Sustainable Development, 3 (4), 248-251.

Mabogunje, A. (2004). Framing the fundamental issues of sustainable development. [Online] Available: http://www.start.org/links/cap_build/advanced_institutes/institute3/p3_documents_folder/Mabogunje.doc (August 20, 2010)

Magnani, E. \& Tubb, A. (2008). The link between economic growth and environmental quality: what is role of demographic change? International Jour. of Global Environmental Issues, 8 (4), 365-391. http://dx.doi.org/10.1504/IJGENVI.2008.019370

Makarov, P. (2010). Intellectual capital as an indicator of a sustainable development. Journal of Sustainable Development, 3 (3), 85-90.

Marler, T. (2009). A study of multi-objective optimization methods: for engineering applications. Saarbrücken, 
Germany: VDM Verlag.

Marler, T. \& Arora, J. S. (2004). Survey of multi-objective optimization methods for engineering. Structural and Multidisciplinary Optimization, 26, 369-395. http://dx.doi.org/10.1007/s00158-003-0368-6

Max-Neef, M. (1995). Economic growth and quality of life: A threshold hypothesis. Ecological Economics, 15, 115-118. http://dx.doi.org/10.1016/0921-8009(95)00064-X

Porritt, J. (2006). Capitalism as if the world mattered. London: Earthscan.

Postel, S. (1990). Toward a new 'eco'-nomics. World-Watch, 3 (5), 20-28.

Rao, R. R., Naidu, S. R. \& Rohana, J. (2009). A critical review of the methods used to estimate the cost of an adequate education. Journal of Sustainable Development, 1 (3), 98-102.

Redman, C. L. (1999). Human impact on ancient environment. Tucson, Az, USA: Univ. of Arizona Press.

Savag, V. R. (2006). Ecology matters: sustainable development in Southeast Asia. Sustainability Science, 1 (1), 37-63. http://dx.doi.org/10.1007/s11625-006-0002-9

Segalas, J., Ferrer-Balas, D., Svanstrom, M., Lundqvist, U. \& Mulder, K. F. (2009). What has to be learnt for sustainability? A comparison of bachelor engineering education competences at three European universities. Sustainability Science, 4 (1), 17-27. http://dx.doi.org/10.1007/s11625-009-0068-2

Shaharir, b. M. Z. (2003). Some specific methodologies of relating mathematical sciences and Islam. Journal of Islamic Science, MAAS, India, 19 (1-2), 111-126.

Shaharir, b. M. Z. (2006). A new approach to the Western concept of optimum and several new concepts of optimum in our own mould. Kesturi, Jurnal Akademi Sains Islam Malaysia, 16 (1-2), 55-96.

Shaharir, b. M. Z. (2008). Economics of development versus economics of happiness. Jawhar. Jurnal Kajian Ketamadunan Malaysia, 5 (1), 1-45.

Shaharir, b. M. Z. (2005). Mathematical sciences and management. Journal. of Quality Measurement Analysis/JuSQA , Universiti Kebangsaan Malaysia, 1 (1), 1-43.

Shaharir, b. M. Z. \& Rohani, bt. A. R. (1996). Influence of value system in a deterministic utility optimization: Towards a theory which is more compatible with Islam. Prosiding simposium kebangsaan sains matematik ke-VII. (pp 290-296). Intitut Teknologi Mara, Shah Alam, Selangor, Malaysia. (In Malay)

Sideris, L. (2007). Evolving environmentalism: the role of ecotheology in creation/evolution controversies. Worldviews: Global Religions, Culture, and Ecology, 11 (1), 58-82.

Simon, H. (1957). Models of man. New York: John Wiley.

Singer, M. (2010). Eco-nomics: are the planet-unfriendly features of capitalism barriers to sustainability? Sustainability, 2 (1), 127-144. http://dx.doi.org/10.3390/su2010127

Smorch, P. (2010). Optimization and sustainability - A winning combination. GCI Magazine. March. [Online] Available: http://www.gcimagazine.com/ business/manufacturing/ supplychain/ 86257672.html. (July 25, 2010)

Sunar, M. \& Kahraman, R. (2001). A comparative study of multiobjective optimization methods in structural design. Turkish Journal of Engineering and Environmental Sciences, 25, 69-78.

Waytz, A. (2010). The psychology of the taboo trade-off. Scientific American. March, 19, 16.

White, A. (2010). Religious environmentalism as a vital contribution to sustainability. Journal of Enterprising Communities: People and Places in the Global Economy, 4 (3), 268-278. http://dx.doi.org/10.1108/17506201011068255

White, L. (1967). The historical roots of our ecological crisis. Science, 155, 1203-1207. http://dx.doi.org/10.1126/science.155.3767.1203

Yusuf Ali, The Holy Quran. http://www.harunyahya.com/Quran_translation/Quran_translation_index.php

Zhou, Z., Cheng, S. \& Hua, B. (2000). Process industries with sustainability considerations. Computers \& Chemical Engineering, 24 (2-7), 1151-1158.

\section{Notes}

Note 1. al-Qur'aan, is the sacred book for Muslims. It contains 144 Chapters or Suraht and 6666 Verses or Ayahts, thus our symbhol x:y means Chapter/Suraht $\mathrm{x}$ and Verse/Ayaht y. We use the translated version by Yusuf Ali, The Holy Quran which available online. 
Note 2. The Arabic word, wusta, is the root word for the the term wasațan in the quranic expression, ummatan wasațan (people who practice wusta) in al-Qur'aan 2: 143. Here, in this verse, the God says that the best practice in whatever we do is at the level of wusta. 